\title{
Análise pós-colheita de goiabas revestidas com fécula de mandioca e óleo essencial de canela
}

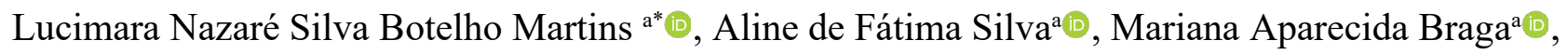 \\ Celeste Maria Patto de Abreu ${ }^{\mathrm{a}}$
}

a Universidade Federal de Lavras, Brasil

*Autor correspondente (lucimarabotelho62@gmail.com)

\section{N F O}

\section{Keyworks}

Psidium guajava

film biopolymers chemical composition storage

\begin{abstract}
A B S T R A C T
Post-harvest analysis of guavas coated with cassava starch and cinnamon essential oil.

Guava is a perishable fruit susceptible to a large amount of post-harvest losses. Biodegradable coatings have been studied as an alternative to reduce these losses. This study aimed to evaluate the chemical composition of guavas 'Pedro Sato' coated with cassava starch with or without the essential oil of cinnamon, submitted to three treatments: control, starch and starch $2 \%+2 \%$ essential oil of cinnamon $0.01 \%$ and stored at $25^{\circ} \mathrm{C}$ and $76 \pm 5 \% \mathrm{RH}$ for 8 days. The experimental design in a factorial $3 \times 5$ ( 3 treatments x 5 times analyzes, $0,2,4,6$ and 8 ) with 3 replicates of 3 fruits, were studied: weight loss, $\mathrm{pH}$, soluble solids, titratable acidity, sugars total and reducing sugars and ascorbic acid. The weight loss, $\mathrm{pH}$ and soluble solids content increased, while the acidity decreased in all treatments. Treatments starch and starch $2 \%+2$ cinnamon essential oil $0.01 \%$ on the eighth day had lower levels of total sugars than control. Reducing sugars increased in all treatments during the days of storage, while ascorbic acid decreased, but to a lesser extent in treatments starch $2 \%$ and starch + essential oil of cinnamon $0.01 \%$. The starch $2 \%+$ essential oil of cinnamon $0.01 \%$ represents good alternative for post-harvest guava conservation, maintaining the chemical characteristics of the fruit without undesirable changes.
\end{abstract}

\section{R E S U M O}

A goiaba é um fruto perecível susceptível a uma grande quantidade de perdas na pós-colheita. Revestimentos biodegradáveis vêm sendo estudados como uma alternativa para reduzir essas perdas. Este trabalho teve como objetivo avaliar a composição química de goiabas 'Pedro Sato' revestidas com fécula de mandioca associada ou não ao óleo essencial de canela, submetidas a três tratamentos: controle, fécula $2 \%$ e fécula $2 \%$ + óleo essencial de canela $0,01 \%$, e armazenadas a $25^{\circ} \mathrm{C}$ e $76 \% \pm 5$ UR, por 8 dias. Utilizou-se delineamento experimental em esquema fatorial $3 \times 5$ ( 3 tratamentos $\times 5$ tempos de análises, $0,2,4,6$ e 8 ) com 3 repetições de 3 frutos, sendo avaliados: $\mathrm{pH}$, sólidos solúveis, acidez titulável, açúcares totais e redutores e ácido ascórbico. $\mathrm{O} \mathrm{pH}$ e o teor de sólidos solúveis aumentaram, enquanto a acidez diminuiu em todos os tratamentos. Os tratamentos fécula $2 \%$ e fécula $2 \%+$ óleo essencial de canela $0,01 \%$ apresentaram no oitavo dia teores de açúcares totais menores que o controle. Os açúcares redutores aumentaram nos três tratamentos durante os dias de armazenamento, enquanto o ácido ascórbico diminuiu, porém de forma menos acentuada nos tratamentos fécula $2 \%$ e fécula $2 \%+$ óleo essencial de canela $0,01 \%$. A fécula $2 \%$ + óleo essencial de canela $0,01 \%$ representam uma boa alternativa para a conservação pós-colheita da goiaba, mantendo as características químicas do fruto, sem alterações indesejáveis. 


\section{INTRODUÇÃO}

A goiaba (Psidium guajava L.) pertencente à família Myrtaceae, composta por mais de 70 gêneros e 2800 espécies, distribuídas nas regiões tropicais e subtropicais, é um fruto bastante atraente, devido à sua cor e aroma agradável.O frutopode ser consumido in natura e possui um alto teorde vitamina $C$, podendo ser três a seis vezes maiores do que na laranja, bem como o teor de licopeno, que é o dobro do encontrado em frutos como o tomate (Silva et al., 2018).

A goiaba apresenta uma alta taxa de respiração e rápido amadurecimento, o que leva a perecer durante o armazenamento. Dessa forma, o seu tempo de comercialização é relativamente pequeno. Após a colheita, seu tempo de vida útil é de aproximadamente 3 a 5 dias, categorizando-a como um produto muito perecível. Os principais indicadores da redução da perda de qualidade da goiaba pós-colheita são o amolecimento e murchamento, perda de cor e brilho da casca e incidência de doenças. (Botelho et al., 2016; Rocha et al., 2020).

Neste contexto, é interessante avaliar o uso de revestimentos comestíveis para melhorar a qualidade das goiabas durante o período de armazenamento (Aquino et al., 2015). Revestimentos comestíveis têm sido utilizadospara aumentar a vida útil de frutos que apresentam alta atividade metabólica. Esses revestimentos podem ser à base de polissacarídeos, como o amido, sendo considerado como alternativa para retardar a respiração, degradação da parede celular, transpiração e também restringir a ação de microrganismos, preservando assim a qualidade dos frutos e vegetais (Nair et al., 2018).

Assim, este trabalho teve como objetivo avaliar as alterações ocorridas nos parâmetros de $\mathrm{pH}$, acidez titulável, açúcares redutores e não redutores e vitamina C nos frutos de goiabas 'Pedro Sato', revestidas com fécula de mandioca associada ao óleo essencial de canela, durante o armazenamento em temperatura ambiente.

\section{MATERIAL E MÉTODOS}

Foram utilizadas goiabas da cultivar Pedro Sato adquiridas de um pomar comercial, no município de Lavras (MG). Foram colhidos 150 frutos e selecionados 135. Após a colheita os frutos foram levados para o Laboratório de Bioquímica da Universidade Federal de Lavras - (UFLA), onde foram selecionados quanto ao tamanho, grau de maturação e ausência de injúria. Estes foram lavados em água corrente e em seguida secos à temperatura ambiente. Para a obtenção do óleo essencial (OE) foi utilizado a canela em pau, obtida no comércio local. OE foi extraído no Laboratório de Produtos Naturais do Departamento de Química, na Universidade Federal de Lavras. A técnica de extração utilizada foi da hidrodestilação, em aparelho de Clevenger modificado, adaptado a um balão de fundo redondo (Anvisa, 2010).

A preparação do revestimento biodegradável (2\%) foi realizado conforme descrito por Botelho et al. (2016). Foram avaliados os parâmetros: a) $\mathrm{pH}$ : utilizou-se pHmetro digital QUIMIS, modelo Q400AS; b) Acidez total titulável (ATT): determinado por titulação, utilizando como indicador a fenolftaleína, segundo as normas analíticas do Instituto Adolfo Lutz (2004), e os resultados expressos em \% de ácido cítrico; c) Sólidos Solúveis (SS): determinados por refratometria de acordo com AOAC (2002), utilizando-se um refratômetro digital (modelo REF 121) e os resultados foram expressos em ${ }^{\circ}$ Brix; d) Açúcares totais (AT), redutores (AR) e não redutores (ANR): foram extraídos segundo o método descritos por Lane-Enyon, citado pela AOAC (2002) e doseamento foi realizado segundo a técnica de Somogyi, adaptada por Nelson (1944)

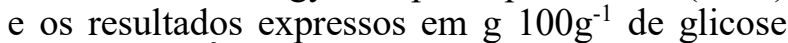
na polpa; e) Ácido ascórbico: foi determinado pelo método colorimétrico, utilizando 2,4dinitrofenilhidrazina, segundo Strohecker e Henning (1967) e os resultados expressos em mg $100 \mathrm{~g}^{-1}$ de ácido ascórbico.

$\mathrm{O}$ delineamento experimental utilizado foi o inteiramente casualizado (DIC), com três repetições, em esquema fatorial $3 \times 5$, sendo os tratamentos (Controle $(\mathrm{C})$, fécula de mandioca $2 \%$ (F) e fécula de mandioca $2 \%$ +óleo essencial de canela $0,01 \% \quad(\mathrm{~F}+\mathrm{OE}))$ em 5 tempos de armazenamento ( $0,2,4,6$ e 8 dias). Os resultados foram submetidos a análise de variância pelo programa SANEST (Zonta e Machado, 1991) e quando houve diferença significativa, aplicou-se regressão.

\section{RESULTADOS E DISCUSSÃO}

$\mathrm{Na}$ figura 1 observa-se que houve diferença significativa $(\mathrm{p}<0,05)$ para $\mathrm{o} \mathrm{pH}$ das goiabas 'Pedro Sato' entre os três tratamentos analisados. Os valores de $\mathrm{pH}$ para o tratamento $\mathrm{C}=3,80$ a 4,21 , enquanto os valores para $\mathrm{F}=3,82$ a 3,97 e para o tratamento $\mathrm{F}+\mathrm{OE}=3,82$ a 4,09 . 


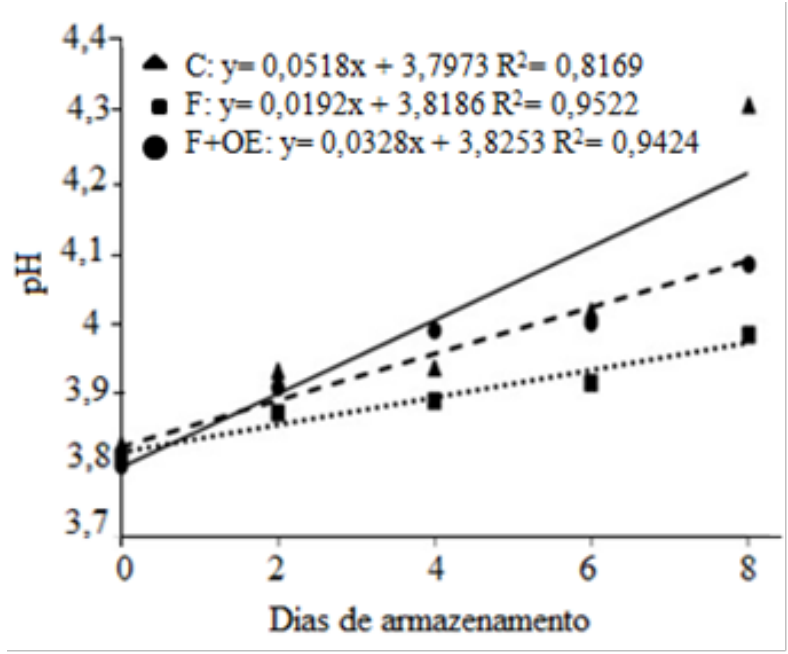

Figura 1 - Curvas e equações de regressão linear do $\mathrm{pH}$ em goiabas 'Pedro Sato' nos tratamentos, C: controle; F: fécula e F+OE: fécula+óleo essencial de canela, ao longo de oito dias de armazenamento.

A partir do $2^{\circ}$ dia, foi observado nos frutos do tratamento $\mathrm{C}$, um aumento nos valores de $\mathrm{pH}$, quando comparados aos outros tratamentos. Isso indica que o amadurecimento nos frutos do tratamento $\mathrm{C}$ foi mais rápido. Os frutos dos tratamentos $\mathrm{F}$ e $\mathrm{F}+\mathrm{OE}$ tiveram o amadurecimento retardado, indicando que a fécula de mandioca foi eficiente em diminuir as reações envolvidas nesse processo.

A acidez total titulável (ATT) em todos os tratamentos não apresentaram diferenças significativas $(p<0,05)$. Houve uma diminuição da ATT nos frutos do tratamento $\mathrm{C}$, o que está de acordo com o comportamento do $\mathrm{pH}$. De acordo com os dados na Tabela 1, ATT dos frutos diminuiu em todos os tratamentos, ao longo dos dias de armazenamento. É possível observar que os frutos tratados com $\mathrm{F}+\mathrm{OE}$ apresentaram maiores teores de acidez quando comparados com os tratamentos $\mathrm{C}$ e $\mathrm{F}$, isso indica um amadurecimento mais lento.

Tabela 1 - Médias da variável acidez total titulável (ATT) da goiaba 'Pedro Sato'.

\begin{tabular}{|c|c|c|c|}
\hline \multicolumn{4}{|c|}{ ATT (\% de ácido cítrico) } \\
\hline Armazenamento & & Tratam & \\
\hline & C & $\mathbf{F}$ & $\mathrm{F}+\mathrm{OE}$ \\
\hline 0 & 0.67 & 0.73 & 0.77 \\
\hline 2 & 0.62 & 0.69 & 0.73 \\
\hline 4 & 0.56 & 0.62 & 0.63 \\
\hline 6 & 0.50 & 0.54 & 0.62 \\
\hline 8 & 0.44 & 0.46 & 0.54 \\
\hline Médias & $0.56 \mathrm{C}$ & $0.61 \mathrm{~B}$ & $0.66 \mathrm{~A}$ \\
\hline
\end{tabular}

Médias seguidas por letras distintas diferem entre si ao nível de significância de 5\% de probabilidade pelo teste Tukey. Tratamentos - C: controle; F: fécula e F+OE: fécula+óleo essencial de canela ao longo de oito dias de armazenamento.

Francisco et al. (2020) analisando o prazo de validade de goiabas revestidas com amido biodegradável e filmes à base de celulose, observaram uma diminuição na acidez total titulável a partir do $6^{\circ}$ dia de avaliação, sugerindo que essa diminuição é devido a hidrólise da pectina, liberando ácido galacturônico, e a consequente produção de ácidos orgânicos na glicólise, seguida pela hidrólise dos ácidos na respiração celular aeróbia.

Morgado et al. (2010), verificaram que para goiabas 'Kumagai' armazenadas sob refrigeração e em temperatura ambiente, houve uma diminuição na acidez total titulável e observaram 
em sua revisão que a ATT de goiabas varia de 0,24 a $1,79 \mathrm{mg}$ de ácido cítrico $\mathrm{mg} 100 \mathrm{~g}^{-1}$. A acidez é um dos principais componentes do sabor, no entanto, a aceitação do fruto depende do balanço entre a quantidade existente de ácidos e açúcares (Demartelaere et al., 2015).

Os teores de sólidos solúveis (SS) variaram significativamente em função do tempo de armazenamento (Figura 2A).
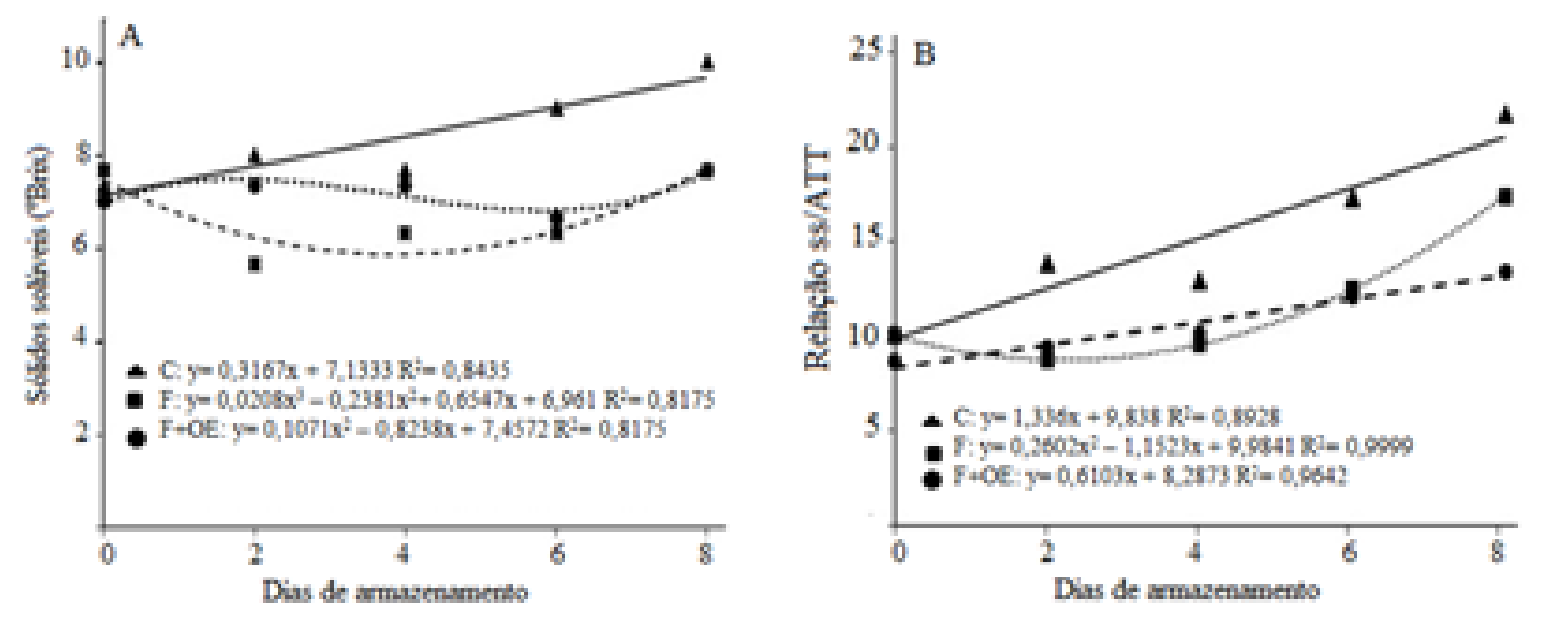

Figura 2 - Curvas e equações de regressão representativa dos teores de sólidos solúveis (A) e relação de sólidos solúveis /acidez total titulável (SS/ATT); (B) presentes em goiabas 'Pedro Sato' nos tratamentos, C: controle; F: fécula e F+OE: fécula+óleo essencial de canela ao longo de oito dias de armazenamento.

No tratamento $\mathrm{C}$ houve um aumento linear no teor de SS, atingindo no $8^{\circ}$ dia $10{ }^{\circ}$ Brix. Esse aumento é justificado pela degradação de polissacarídeos da parede celular e da perda de massa fresca, que neste tratamento foi mais expressiva. Nos tratamentos $\mathrm{F}$ e F+OE foi possível observar uma menor variação nos teores de SS ao longo do armazenamento, o que indica um amadurecimento mais lento, devido ao revestimento fécula de mandioca. Quirino et al. (2018) obteve resultados semelhantes no estudo com goiabas 'Paluma' recobertas com fécula de mandioca e pectina. As goiabas recobertas com fécula de mandioca nas concentrações 4 e $6 \%$ foram capazes de retardar o acúmulo de sólidos solúveis em relação aos frutos não recobertos.

Pinto et al. (2009), analisando goiabas 'Kumagai' e 'Pedro Sato' observaram que os teores de SS dos frutos colhidos verde-amarelado foram maiores durante todo armazenamento, em ambas cultivares, apresentando no $9^{\circ}$ dia teores de $6,91^{\circ}$ Brix e de $8,71^{\circ}$ Brix, respectivamente.

Segundo Demartelaere et al. (2015), a relação SS/ATT é utilizada para avaliar o grau de maturação e, portanto, o sabor da maioria dos frutos e, quando avaliada pode auxiliar na compreensão dos processos metabólicos em progresso. $\mathrm{O}$ tratamento $\mathrm{F}+\mathrm{OE}$ apresentou menor relação de SS/ATT no final do armazenamento, 13,17 , indicando que a associação da fécula + óleo essencial de canela foi eficiente em retardar o processo de amadurecimento e trocas gasosas durante o período de armazenamento (Figura 2B).

Os frutos do tratamento $F$ também apresentaram relação SS/ATT menores do que os frutos controle, 17,41, porém, superiores à observada no tratamento $\mathrm{F}+\mathrm{OE}$. $\mathrm{O}$ tratamento controle apresentou no $8^{\circ}$ dia de armazenamento, relação de SS/ATT de 20,53, o que caracteriza maior degradação da parede celular. Azzolini et al. (2004) observaram que em goiabas 'Pedro Sato' houve um aumento na relação SS/ATT, e esse resultado encontrado foi semelhante ao obtido nesse trabalho.

O teor de açúcares totais (AT) aumentou, em todos os tratamentos durante o período de armazenamento (Figura 3A). Esse aumento pode ter ocorrido em função da degradação de polissacarídeos da parede celular, resultando na elevação da concentração de açúcares. 

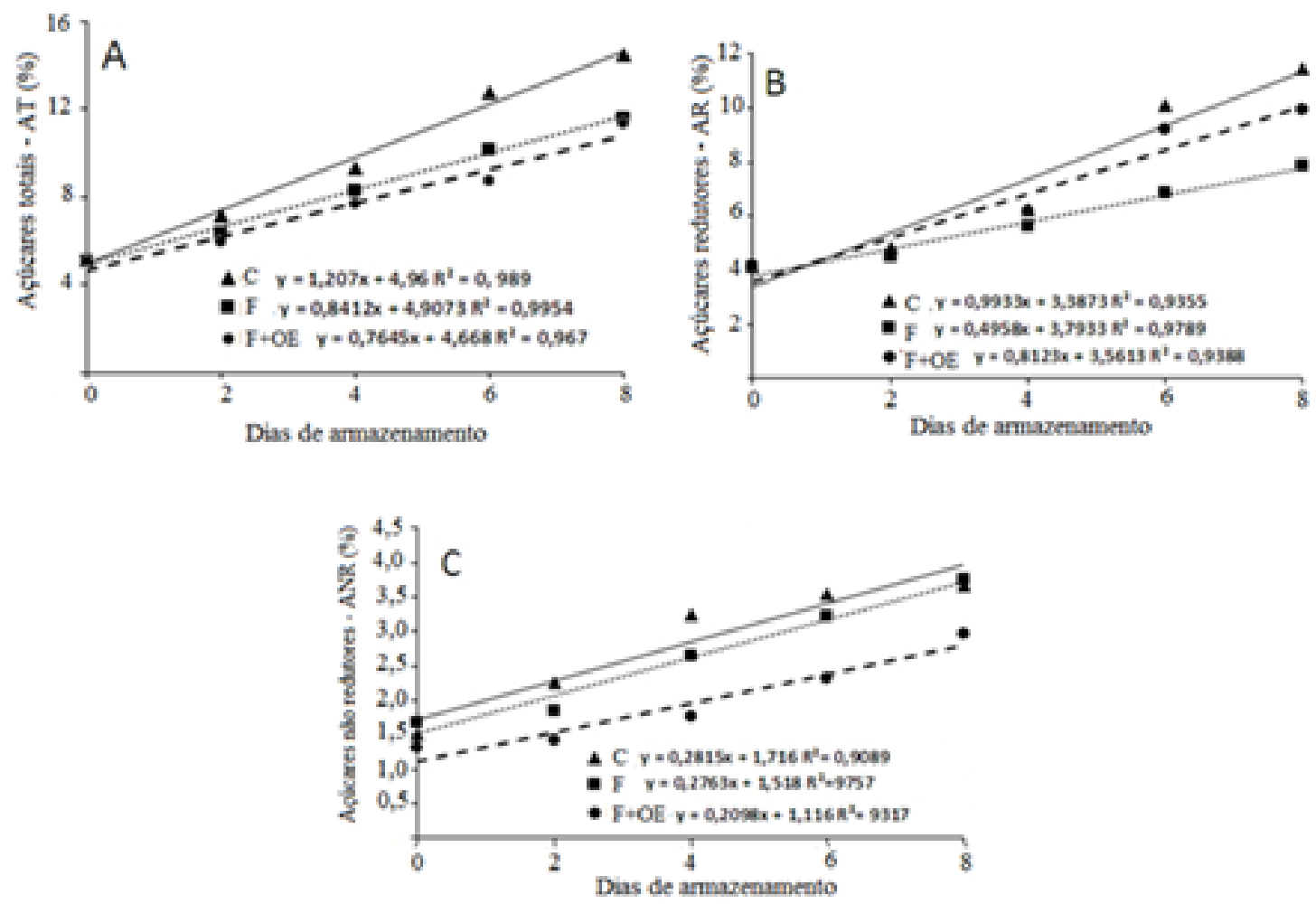

Figura 3 - Curvas e equações de regressão linear de goiabas 'Pedro Sato' nas diversas unidades ao longo dos oito dias de armazenamento. A) Açúcares totais (AT), B) Açúcares redutores (AR) e C) Açúcares não redutores (ANR).

O teor de AT encontrado no fruto do tratamento $\mathrm{C}$ variou de $4,96 \%$ a $14,62 \%$. O tratamento $\mathrm{F}$ obteve valores de $4,91 \%$ a $11,64 \%$ e o tratamento $\mathrm{F}+\mathrm{OE}$ foi encontrado valores de $4,67 \%$ a $10,78 \%$. Esse tratamento teve o amadurecimento retardado e liberação mais lenta dos açúcares de polímeros de parede celular contribuindo para um menor teor de AT. Vila et al. (2007), estudando as características químicas e bioquímicas de goiabas armazenadas sob refrigeração e atmosfera modificada, verificaram aumento linear dos teores de AT em todos os tratamentos. A regressão apresentada na Figura 3B mostra um aumento no teor de açúcares redutores (AR) em todos os tratamentos durante $\mathrm{O}$ amadurecimento. $\mathrm{O}$ tratamento $\mathrm{C}$ apresentou teores de AR de 3,39\% no primeiro dia de avaliação e de $11,37 \%$ no oitavo dia de avaliação. Os tratamentos $\mathrm{F}$ e $\mathrm{F}+\mathrm{OE}$ apresentaram $3,79 \%$ e $3,56 \%$ no primeiro dia de avaliação e $7,76 \%$ e 10,06\%, respectivamente, teores estatisticamente menores que os observados no tratamento $\mathrm{C}$, mostrando que o amadurecimento foi mais lento nesses frutos, devido ao menor processo de hidrólise de polissacarídeos, hemicelulose e substâncias pécticas da parede celular.

Os resultados encontrados mostraram aumento de açúcares não redutores (ANR) até o final do armazenamento (Figura 3C). No $8^{\circ}$ dia de armazenamento os frutos dos tratamentos $\mathrm{C}, \mathrm{F}$ e $\mathrm{F}+\mathrm{OE}$ apresentaram valores de ANR 3,97\%, $3,73 \%$ e $2,80 \%$, respectivamente. O tratamento $\mathrm{F}+\mathrm{OE}$ apresentou menores teores de ANR, sugerindo que esse tratamento reduziu a hidrólise da sacarose, retardando o processo de senescência dos frutos. Os resultados encontrados neste experimento foram similares aos reportados por Vila et al. (2007), que analisando goiabas 'Pedro Sato' revestidas com os tratamentos de fécula de mandioca $2 \%, 3 \%$ e $4 \%$, associada a refrigeração, observaram que os teores de ANR aumentou ao longo do armazenamento.

Houve diminuição de ácido ascórbico ao longo dos dias de armazenamento em todos os tratamentos (Figura 4). 


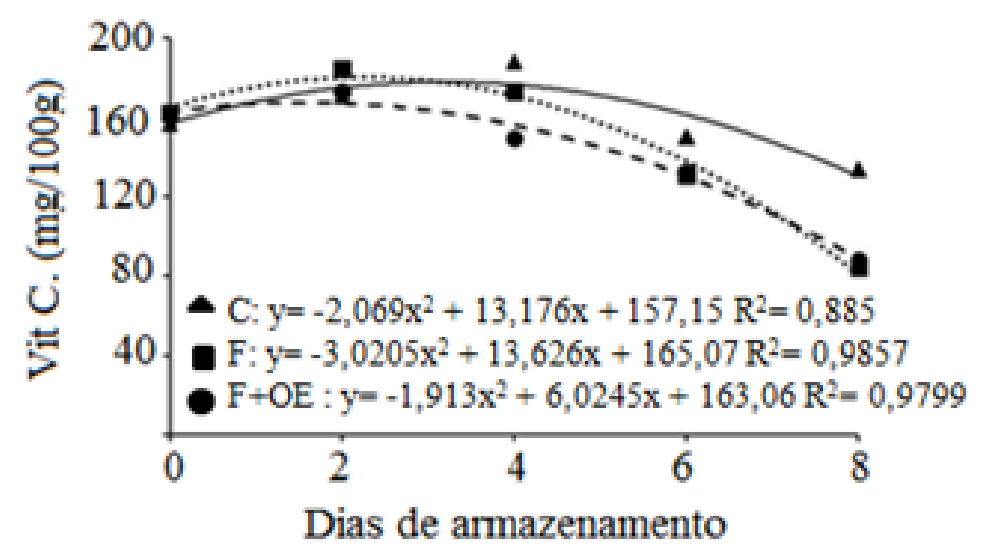

Figura 4 - Curvas e equações de regressão linear dos valores de ácido ascórbico presentes em goiabas 'Pedro Sato' em diferentes tratamentos ao longo de oito dias de armazenamento.

No $8^{\circ}$ dia, observou-se para os tratamentos $\mathrm{F}$ e $\mathrm{F}+\mathrm{OE}$ teores de ácido ascórbico de $80,77 \mathrm{mg} .100$ $\mathrm{g}^{-1}$ e $88,82 \mathrm{mg} \cdot 100 \mathrm{~g}^{-1}$, respectivamente. No tratamento $\mathrm{C}$, a quantidade de ácido ascórbico encontrada foi de $130.10 \mathrm{mg} \cdot 100 \mathrm{~g}^{-1}$. O aumento inicial no teor de ácido ascórbico está relacionado à maior síntese de intermediários metabólicos precursores do ácido ascórbico e a sua posterior diminuição, à oxidação dos ácidos orgânicos durante $\mathrm{O}$ amadurecimento. Os frutos do tratamento $\mathrm{C}$ apresentaram um amadurecimento mais rápido, isso contribuiu para síntese maior de ácido ascórbico até o $4^{\circ}$ dia. A partir do $4^{\circ}$ dia decresceu, quando comparados aos frutos dos outros dois tratamentos. A queda do ácido ascórbico durante o armazenamento, se deve ao fato que o ácido ascórbico é muito instável à luz e temperatura. Quirino et al. (2018) relataram que o teor de ácido ascórbico durante os dias de avaliação das goiabas revestidas com fécula de mandioca decaíram. Consideraram que o uso dos revestimentos pode manter uma menor concentração de oxigênio ao redor dos frutos, reduzindo a suscetibilidade do ácido ascórbico ao oxigênio e diminuindo as perdas das propriedades antioxidantes durante o armazenamento. Hong et al. (2012) no estudo do efeito do revestimento de quitosana $1 \%$ e $2 \%$ sobre goiabas armazenadas em refrigeração, observaram que o teor de ácido ascórbico na polpa da goiaba diminuiu gradualmente nos dois tratamentos.

A aparência interna e externa do fruto ao final do oitavo dia de avaliação pode ser observado na Figura 5. Os parâmetros avaliados indicaram que o amadurecimento do fruto ao final do oitavo dia de avaliação foi mais pronunciado para o tratamento C. Já nos tratamentos $\mathrm{F}$ e $\mathrm{F}+\mathrm{OE}$, os parâmetros estudados foram retardados, ocorrendo uma liberação mais lenta dos açúcares de polímeros da parede celular, obtendo ao final da avaliação frutos com a aparência similar ao dia da colheita, indicando a redução na senescência dos frutos.

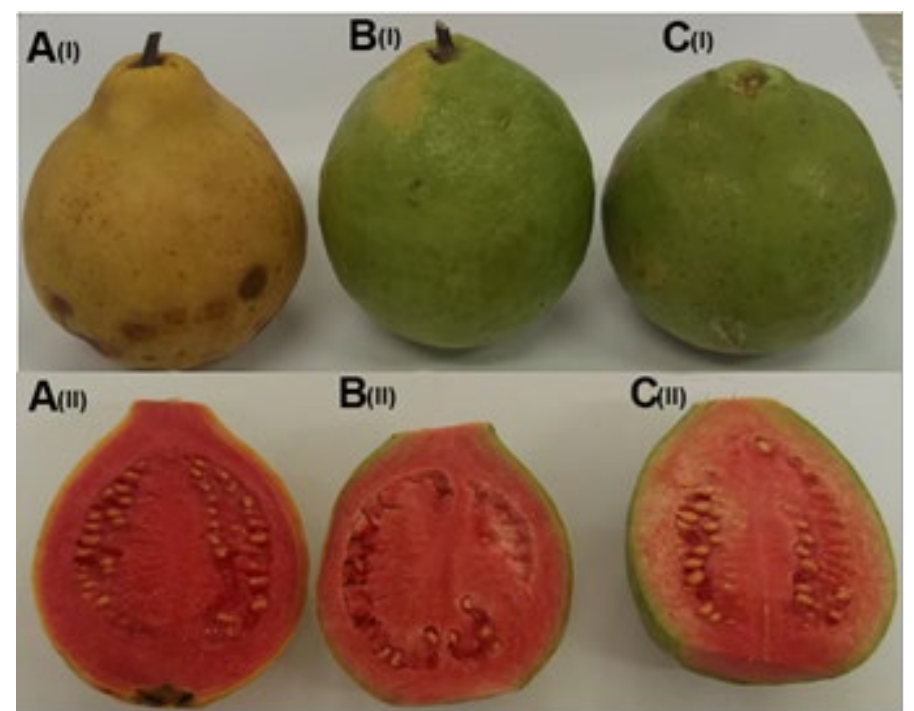

Figura 5 - Goiabas 'Pedro Sato' no oitavo dia de avaliação. A) tratamento controle (C), B) tratamento Fécula $(\mathrm{F})$ e C) tratamento fécula $+\mathrm{OE}(\mathrm{F}+\mathrm{OE})$. (I) Fruto inteiro (II) parte interna). 
Esses resultados complementam o trabalho de Botelho et al. (2016) e confirmam que a combinação do revestimento biodegradável associado ao óleo essencial de canela é uma alternativa promissora para prolongar o tempo de armazenamento da goiaba.

\section{CONCLUSÕES}

Os tratamentos $\mathrm{F}$ e $\mathrm{F}+\mathrm{OE}$ demonstraram ser uma boa alternativa para a conservação póscolheita da goiaba, mantendo a qualidade dos frutos por mais tempo. A composição química dos frutos tratados com $\mathrm{F}$ e $\mathrm{F}+\mathrm{OE}$ não promoveram mudanças indesejáveis nos frutos. A combinação do revestimento biodegradável a base de fécula de mandioca associado ao óleo essencial de canela se mostrou promissora na conservação de goiabas após a colheita, podendo ser considerada uma boa alternativa para aumentar o tempo de comercialização deste fruto perecível, mantendo as características físico-químicas do mesmo.

\section{AGRADECIMENTOS}

Os autores agradecem aos órgãos de fomento Conselho Nacional de Desenvolvimento Científico e Tecnológico, Coordenação de Aperfeiçoamento de Pessoal de Nível Superior e Fundação de Amparo à Pesquisa de Minas Gerais (CNPq/CAPES/FAPEMIG), Brasil.

\section{REFERÊNCIAS BIBLIOGRÁFICAS}

Agência Nacional de Vigilância Sanitária (ANVISA). Farmacopeia brasileira. Brasília, 5. ed., v. 1, p. 198-199. 2010. Disponível em:

$<$ http://www.anvisa.gov.br/hotsite/cd_farmacopeia/index.h tm>. Acesso em: 12 dez. 2017.

Association of Official Analytical Chemistry (AOAC). Official methods of analysis of the Association of Official Analytical Chemistry, 1275p. 2002.

Aquino AB, Blank AF, Santana LCLA. Impact of edible chitosan-cassava starch coatings enriched with Lippia gracilis Schauer genotype mixtures on the shelf life of guavas (Psidium guajava L.) during storage at room temperature. Food Chemistry, v. 171, p.118-116, 2015. https://doi.org/10.1016/j.foodchem.2014.08.077.

Azzolini M, Jacomino AP, Bron IU. Índices para avaliar qualidade pós-colheita de goiabas em diferentes estádios de maturação. Pesquisa Agropecuária Brasileira, v. 39, n. 2, p. 139-145, 2004. https://doi.org/10.1590/S0100204X2004000200006.

Botelho LNS, Rocha DA, Braga MA, Silva A, de Abreu CMP. Quality of guava cv. 'Pedro Sato' treated with cassava starch and cinnamon essential oil. Scientia Horticulturae, v.209, p.214-220, 2016.

https://doi.org/10.1016/j.scienta.2016.06.012.
Demartelaere ACF, Guimarães GHC, Silva JA, Luna RG, Nascimento LC. Extratos vegetais no controle da antracnose e na conservação da qualidade em frutos de mamoeiro. Revista Brasileira de Plantas Medicinais, v.17, n.4, p.10411048, 2015.

Francisco CB, Pellá MG, Silva AO, Raimundo KF, Caetano J, Linde GA, Colauto NB. Dragunski DC. Shelf-life of guavas coated with biodegradable starch and cellulosebased films. International Journal of Biological Macromolecules, v. 152, p. 272-279, 2020.

https://doi.org/10.1016/j.ijbiomac.2020.02.249.

Hong K, Xie J, Zhang L, Sun D, Gong D. Effects of chitosan coating on postharvest life and quality of guava (Psidium guajava L.) fruit during cold storage. Scientia Horticulturae, v. 144, p.172-178, 2012. https://doi.org/10.1016/j.scienta.2012.07.002.

Instituto Adolfo Lutz (IAL). Normas Analíticas: Métodos Físico-químicos para Análise de Alimentos. 4 ed., $1^{\text {a }}$ edição digital, 2004.

Morgado CMA, Durigan JF, Lopes VG, Santos LO. Conservação pós-colheita de goiabas 'Kumagai': Efeito do estádio de maturação e da temperatura de armazenamento. Revista Brasileira Fruticultura, v. 32, n. 4, p.1001-1008, 2010. https://doi.org/10.1590/S0100-29452010000400008.

Nair MS, Saxena AK, Kaur C. Effect of chitosan and alginate based coatings 288 enriched with pomegranate peel extract to extend the postharvest quality of guava 289 (Psidium guajava L.). Food Chemistry, v. 240, p. 245-252, 2018. https://doi.org/10.1016/j.foodchem.2017.07.122.

Nelson NA. A photometric adaptation of Somogyi method for the determination of glucose. Journal of Biological Chemistry, v. 153, n. 2, p. 375-380, 1944. https://doi.org/10.1016/S0021-9258(18)71980-7.

Pinto PM, Jacomino AP, Cavalini FC, Junior LCC, Inoue KN. Estádios de maturação de goiabas 'Kumagai' e 'Pedro Sato' para o processamento. Ciência Rural, v. 40, n. 1, p. 37-43, 2009. https://doi.org/10.1590/S010384782009005000244 .

Quirino AK, Costa JDS, Neto AF, Costa, MS, Sánchez-Sáenz CM. Conservación de las guayabas "Paluma" recubiertas con almidón de yuca y pectin. Dyna, v. 85, n. 204, p. 344351, 2018. https://doi.org/10.15446/dyna.v85n204.63420.

Rocha AM, Costa SC, Lima TS, Silva AF, Barão CE, Pimentel TC, Antonelli-Ushirobira TM, Marcolino VA. Application of cassava starch and corn starch biopolymer in guava postharvest conservation. Brazilian Journal of Development, v. 6, n. 2, p. 6658-6680, 2020. https://doi.org/ $10.34117 / \mathrm{bjdv} 6 \mathrm{n} 2-098$.

Silva WB, Silva GMC, Santana DB, Salvador AR, Medeiros DB, Belghithd I, Silva NM, Cordeiro MHM, Misobutsi GP. Chitosan delays ripening and ROS production in guava (Psidium guajava L.) fruit. Food Chemistry, v. 242, p. 232-238, 2018. https://doi.org/10.1016/j.foodchem.2017.09.052.

Strohecker R, Henning HM. Analisis de vitaminas: métodos comprovados. Madrid:_Paz Montalvo, 428p. 1967.

Vila MTR, Lima LCO, Vilas Boas EVB, Doll Hojo ET, Rodrigues LJ, Paula NRF. Chemical and biochemical caracterization of guavas stored under refrigeration and mod- 
ified atmosphere. Ciência e Agrotecnologia, v. 31, n. 5, p. 1435-1442, 2007. https://doi.org/10.1590/S1413-

70542007000500025 .

Zonta EP, Machado AA. Manual do Sanest: sistema de análise estatística para microcomputadores. Pelotas: UFPel, 102p. 1991. 